\title{
A new composite material based on natural fibres and a thermoset: technology, applications and properties
}

\author{
G. Wuzella \\ Kompetenzzentrum Holz GmbH clo FunderMax Industrie GmbH, \\ Klagenfurter Straße 87-89, A-9300 St. Veit/Glan, Austria
}

\begin{abstract}
The aim of this work was the development of a new composite material based on natural fibres as reinforcement and an acrylic thermoset as binder to investigate the material properties for various applications. All applications were made by forming and curing the composite material in a hot forming press. In a first step the technology for formation of such a composite material was tested: Based on the nonwoven-process natural fibre mats were made, only composed of natural fibres without binder and with different area weights. After that, different technologies of application of binder and additives like hydrophobizing agents were tested. In the second step the material properties (flexural and impact strength, water uptake and moisture expansion, testing for climatic extremes and sound-absorbing properties) were investigated for different applications as function of the density of the pressed parts, the mixing ratio of binder and additives. The following properties can be given as very special features of the material: In comparison with composites made of usual thermoset binders the fabricator has not to apply the resin immediately before processing. Secondly the material can be stored easily, because the curing is started beyond $100^{\circ} \mathrm{C}$, at lower temperatures the binder is thermoplastic. In comparison with composites made of thermoplastic binders, a lesser fraction of binder is necessary and the pressed parts have a very high flexural stiffness. Finally the critical properties like the water uptake and moisture expansion were improved by the addition of hydrophobizing agents.

Keywords: natural fibres, nonwoven, composites, acrylic resin, binding technology.
\end{abstract}




\section{Introduction}

Actual industrial demand for natural fibres has developed over the past few years. Today, the use of natural fibres has become common in some applications; the most important customer is the automotive industry. Technically speaking, the use of natural fibres in automotive applications involves primarily pressmolded composites, produced by the pressing of a nonwoven mat with a binder. Typical uses are in door panels, hat racks, and trunk liners. Two production technologies are commercially employed:

- a blend of natural and polypropylene fibres is processed into a nonwoven mat and pressed into the desired shape under heat ("thermoplastic matrix");

- nonwoven mats are coated with thermosets, such as epoxy resin or polyurethane and moulded. The ultimate material is generated by polymerization and hardening of the resin ("duromeric matrix").

The main reasons for the use of natural fibres are:

- Weight reduction of 10 to $30 \%$

- Good mechanical and manufacturing properties

- Possibility to manufacture complex structural elements from one material in a single pass

- $\quad$ Good performance in accidents (high stability, no splintering)

- Superior environmental balance during material and energetic use

- Occupational health advantages compared to glass fibres

- No emissions of toxic substances

- Overall cost advantage compared to conventional construction

The aim of this work is the development of a new composite material, based on natural fibres as reinforcement but instead of a thermoplastic binder only a thermoset is used to realise a new range of applications. Instead of the commonly used thermosets like epoxy resins, polyurethanes or aqueous phenolic resins, another thermoset is used, which can be processed easier and which corresponds better to the proposition of an ecological awareness.

Due to the machines of the partner company the production of fibre mats is based on the nonwovens technology: dry-laying staple fibres (the fibres are 1 to $20 \mathrm{~cm}$ or longer, but not continuous) by an aerodynamic web formation and mechanically bonded by needle-punching. The term nonwoven is defined as a manufactured sheet, web or bat of directionally or randomly oriented fibres, bonded by friction, and/or cohesion and/or adhesion, excluding paper or products which are woven, knitted, tufted stitch bonded incorporating binding yarns or filaments, or felted by wet milling, whether or not additionally needled. The fibres may be of natural or man-made origin. They may be staple or continuous or be formed in situ $[1,6]$.

\section{Materials}

For composites composed of natural fibres, blends of natural fibres (e.g. flax and kenaf or flax and hemp) are particularly interesting. The finer flax fibres impart 
high stability, but because they impede complete soaking with thermosetting binders, fractures may develop. Only the mixture with coarser fibres like kenaf fibres achieves an optimum balance between stability and complete saturation with the binder. In this project all nonwovens are a mixture of kenaf and flax at the ratio of 50:50.

\subsection{Kenaf fibres}

Kenaf is the term for the plant Hibiscus cannabinus L., a warm season annual closely related to cotton (Gossypium hirsutum L.) and okra (Abelmoschus esculentus L.). The kenaf fibres are gained from the bark of the stem of the plants. The staple fibres have a length of $40-60 \mathrm{~mm}$ and an average thickness of $25 \mu \mathrm{m}$. Because of their mechanical properties they are used as reinforcing fibres in a composite [2].

\subsection{Flax fibres}

Flax fibres are amongst the oldest fibre crops in the world and the use of flax for the production of linen goes back 5000 years. Flax fibres are soft, lustrous and flexible. They are stronger than cotton fibre but less elastic. Because of their mechanical properties they are used as reinforcing fibres in a composite [3].

\subsection{Matrix}

The used matrix system in this work is a reactive aqueous acrylic resin, which is free of phenol and formaldehyde. This one-component resin has good storage stability and cross-links upon heating to $180-220^{\circ} \mathrm{C}$. After the impregnation the fibre mats are dried. The binder begins to cure beyond $100^{\circ} \mathrm{C}$, and semi-finished products impregnated with the acrylic resin therefore have excellent storage stability in comparison to other thermosets (e.g. epoxy resins or polyurethane). During the hot press step the impregnated mats are formed and the resin is crosslinked. Composite parts bound with the acrylic resin show high stiffness and strength and meet the ecological requirements of the automotive industry. To achieve the best mechanical properties and moisture resistance, press moulding is carried out with tool temperatures of about 200 to $220^{\circ} \mathrm{C}$ and cycle times of one minute or less $[4,5]$.

\subsection{Additives}

In this project two types of additives are used to improve the properties of the composite. The first is a borate, which contributes to avoid the creation of mildew, because of the moisture content in nonwoven composed of natural fibres. The second additive is a paraffin wax, which improves the water resistance (water uptake and moisture expansion, influence of climatic extremes on material properties) of the moulded part. In particular the type of paraffin wax has to be stable against acid, because of the acidity of the used acrylic resin [5]. 


\section{Technologies of binding}

The first task of this work was to find a technology to apply the binder to the natural fibres. In the following second task the found technology was adjusted to find the optimised settings for the application. The application process of the binder can be done in two ways. Either the naturals fibres are impregnated before they are laid to fibre mats or the application is done subsequent to the nonwovens process. All 3 tested technologies in this project follow the second way of impregnation with the following pre-adjustments:

- Used binders are liquid, especially aqueous binders

- Additives are mixed together with the binder before impregnating

\subsection{Foam impregnation technology}

The binder is mixed to a foam by a mixing machine and applied to the rotating rolls. The nonwoven, composed of natural fibres, is impregnated by pressure between the roller clearance. After that the impregnated nonwoven is dried in an oven and winded to a roll or cut into formatted pieces.

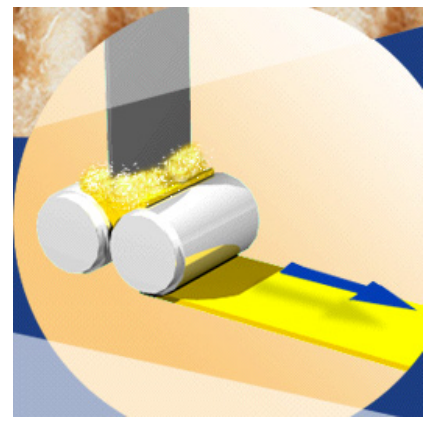

Figure 1: Scheme of impregnation by foam.

\subsubsection{Evaluation of the foam impregnation technology}

+ Energy-saving concerning the drying process of the impregnated nonwoven, because less water is applied to the nonwoven by the foam compared to other impregnation technologies.

- Not all binders can be mixed to foam, sometimes a foaming agent is necessary.

- Thick materials (area weight $>1000 \mathrm{~g} / \mathrm{m}^{2}$ ) require for a complete impregnation high power of the impregnation plant. Experiments demonstrate that the power consumption for thick nonwovens with a width greater than $0.5 \mathrm{~m}$ exceeds the engine power; sometimes a thick nonwoven is not continuously impregnated.

- Additionally a complete impregnation of thick nonwovens causes a very high compression of the natural fibres in the mat, which can lead to damaged fibres.

\subsection{Impregnation technology of glass prepregs}

The nonwoven is pulled through a basin, which is filled with the liquid binder. After the impregnation the excess of binder and water is squeezed out between 
two rolls. After that the impregnated nonwoven is dried in a vertical drying tower and winded to a roll or cut into formatted pieces.

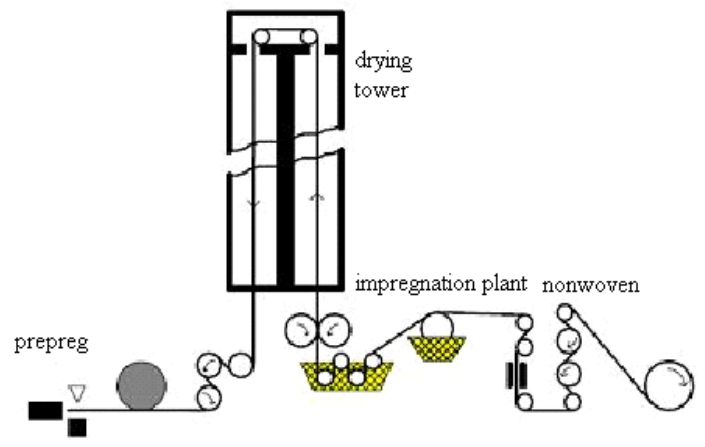

Figure 2: $\quad$ Scheme of impregnation technology of glass pregpregs.

\subsubsection{Evaluation of the impregnation technology of glass prepregs}

+ All liquid binder systems can be used

+ Continuous impregnation for nonwovens in any thickness and width without damaging of fibres or exceeding of engine power limit.

- To guarantee a continuous impregnation of the nonwoven the aqueous binder has to be diluted with further water, which cannot be dried by the drying tower. The vertical drying tower is insufficient to dry the nonwoven quickly enough.

- During storage of the winded impregnated nonwoven the residual moisture and binder migrate and cause inhomogeneity of the impregnation.

\subsection{Foulard dyeing technology}

The apparatus comprises a foulard in which the nonwoven is provided with the binder in a treatment bath and squeezed off to the binder and moisture content. The impregnated nonwoven is winded to a roll, which can be transported to the dryer.

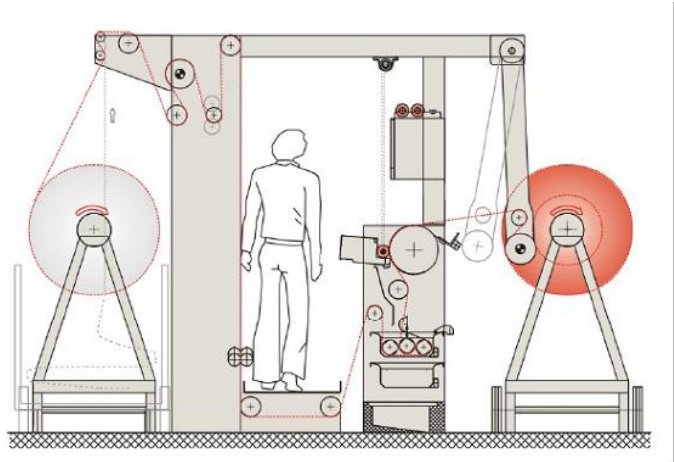

Figure 3: Scheme of a foulard dyeing system. 


\subsubsection{Evaluation of the foulard dyeing technology}

+ All liquid binder systems can be used

+ Continuous impregnation for nonwovens in any thickness and width without damaging of fibres or exceeding of engine power limit.

+ To guarantee a continuous impregnation of the nonwoven the aqueous binder has to be diluted with further water. In fact the horizontal dryer is limited to avoid the curing of the binder but sufficient enough to dry the impregnated nonwoven to a residual moisture of $10 \%$.

- Dimensioning of the dryer and the drying process is more expensive than the foam impregnation technology

\subsection{Choice of the impregnation technology}

Due to the evaluation of the three technologies of binding the decision was made in favour of the foulard dyeing technology. This technology is the easiest way to impregnate the nonwoven continuously without risk to exceed the engine power limit and without risk to damage the fibres because of over-compression. The external horizontal dryer allows drying of the nonwoven to the residual moisture of $10 \%$.

\section{Applications and properties}

The impregnated mats are moulded to composite parts and the following properties complying with DIN standards are tested

Table 1: $\quad$ Measured properties.

\begin{tabular}{|c|c|}
\hline Property & Standard \\
\hline Flexural strength $\left[\mathrm{N} / \mathrm{mm}^{2}\right]$ & DIN EN 310 \\
\hline Flexural modulus of elasticity (MOE) [N/ $\left.\mathrm{mm}^{2}\right]$ & DIN EN 310 \\
\hline Water uptake $[\%]$ & DIN 52351 \\
\hline $\begin{array}{l}\text { Increase of thickness of samples due to moisture } \\
\text { expansion }[\%]\end{array}$ & DIN 52351 \\
\hline Impact strength $\left[\mathrm{mJ} / \mathrm{mm}^{2}\right]$ & DIN EN ISO 179 \\
\hline
\end{tabular}

Many types of applications were made with the impregnated material. Besides door panels, hat racks and trunk liners a roofliner as application should be developed.

\subsection{Mechanical Properties}

Because of the processing of fibre mats (laying and needling) the nonwoven as well as the moulded parts have different mechanical properties subject to the direction a sample is taken. Therefore these properties are proved for two directions, one parallel to the direction of the mat production and one transverse to this direction. Samples in direction of production have higher mechanical strength than samples transverse to this direction. 


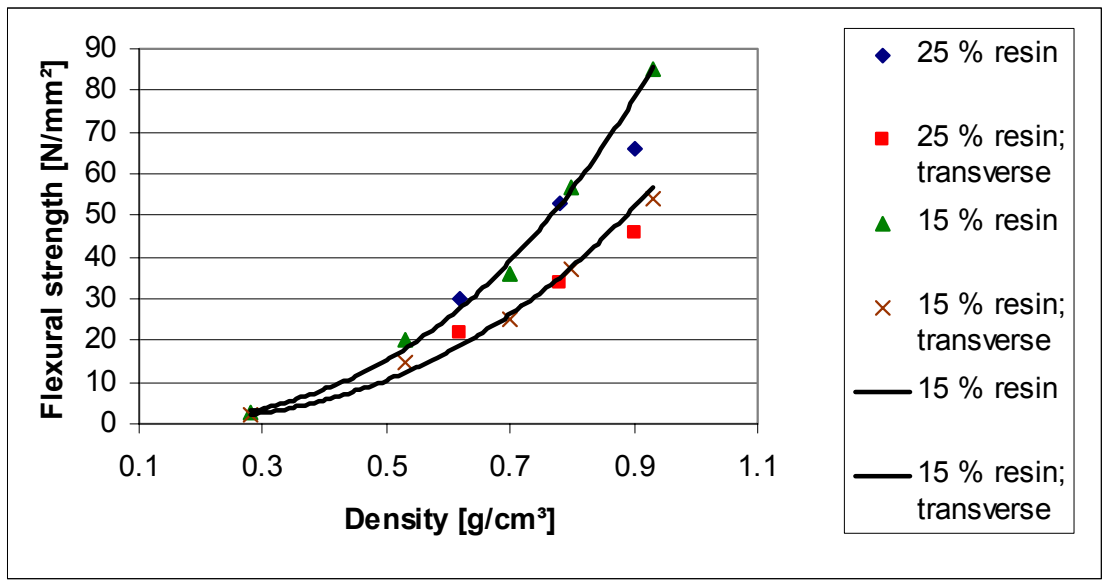

Figure 4: $\quad$ Flexural strength of moulded composites with 2 different contents of binder as function of density, tested in 2 orthogonal directions.

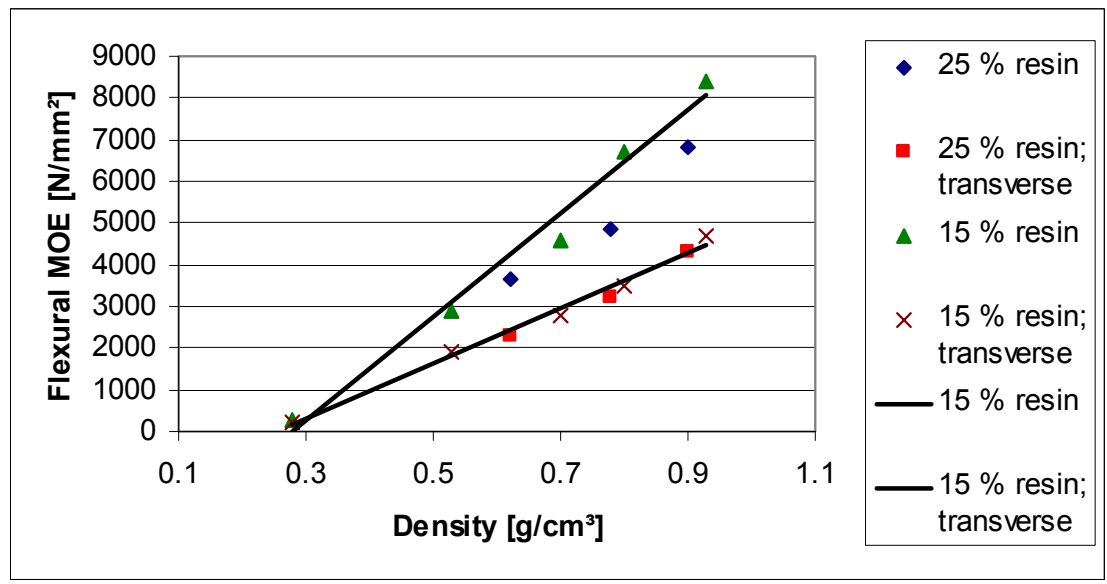

Figure 5: Flexural MOE of moulded composites with 2 different contents of binder as function of density, tested in 2 orthogonal directions.

Both flexural properties, the flexural strength and the flexural modulus of elasticity, primarily depend on the density of the moulded composite. The higher the density of the moulded part is the higher are the flexural properties. The binder content has only a small effect on the flexural properties; for samples in production direction and with a higher density the properties are higher, if the binder content is $15 \%$ instead of $25 \%$. In comparison to other composite materials based on natural fibres the attention should be paid to the high values of flexural properties for samples with a density of $0.9 \mathrm{~g} / \mathrm{cm}^{3}$ and above: samples in production direction have a flexural MOE between 7000 and $8000 \mathrm{~N} / \mathrm{mm}$ and 
a flexural strength between 70 and $85 \mathrm{~N} / \mathrm{mm}^{2}$, samples transverse to this direction have a flexural MOE about $4500 \mathrm{~N} / \mathrm{mm}^{2}$ and a flexural strength of about $50 \mathrm{~N} / \mathrm{mm}^{2}$. The impact strength of all samples is low $\left(10 \mathrm{~mJ} / \mathrm{mm}^{2}\right)$ regardless of binder content and of density.

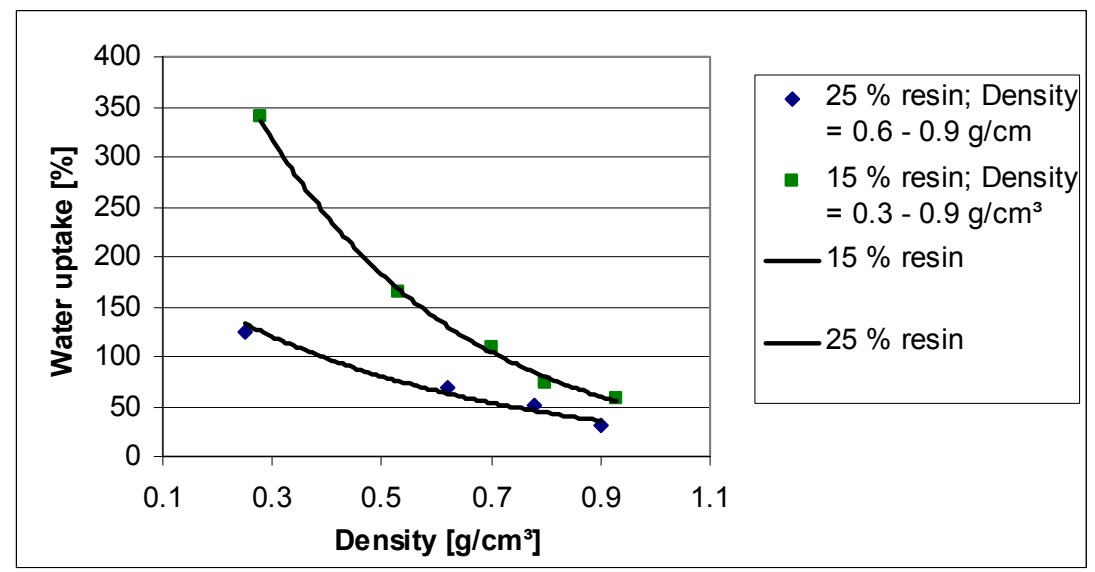

Figure 6: Water uptake of moulded composites with 2 different contents of binder but without hydrophobizing agent as function of density.

\subsection{Water uptake and moisture expansion}

The water uptake primarily depends on the density of the moulded composite. The higher the density of the moulded part is the lower is the water uptake. By higher binder content the ability of water uptake can be decreased. This effect is much higher if the density of the moulded composite is low.

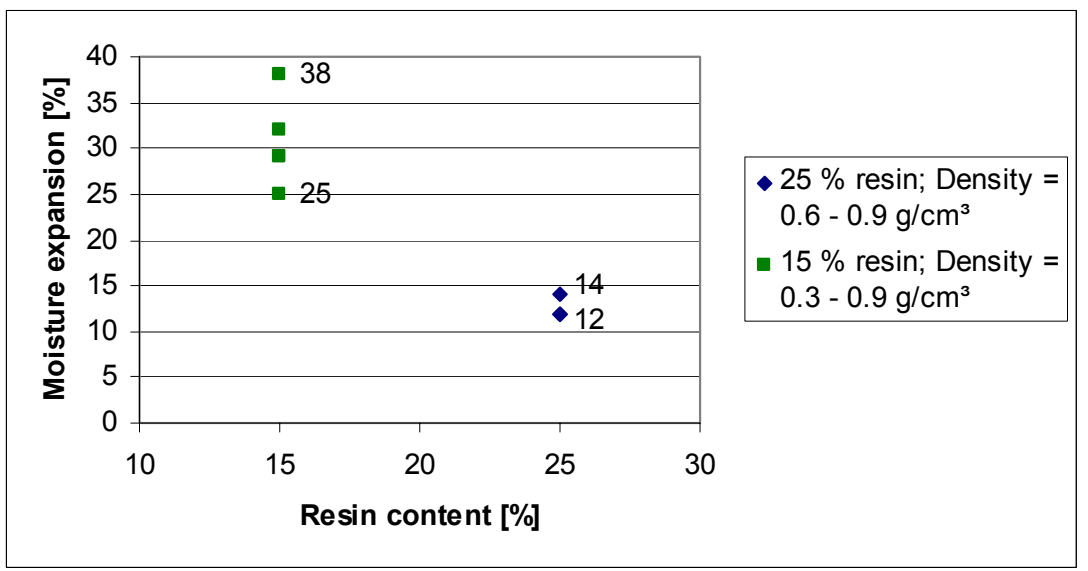

Figure 7: Moisture expansion of moulded composites with 2 different contents of binder but without a hydrophobizing agent. 
The increase of thickness of moulded composites due to moisture depends only on the resin content but not on the density of the moulded part. Higher binder content means that the composite is more rigid against the moisture expansion and the fibres are better protected against water. A composite with low density has besides to the hydrophilic behaviour of natural fibres a high porosity. This explains why the water uptake can be high but at the same time the thickness doesn't increase to the same degree.

\subsection{Improvement of water resistance}

The measured properties like water uptake and moisture expansion are subject of an improvement, mainly for applications with a low density like a roofliner. Hence a hydrophobizing additive can be mixed into the binder.

To improve the water resistance of the moulded composites $1.5 \%$ of additive is sufficient for moulded parts with a density of $0.9-1 \mathrm{~g} / \mathrm{cm}^{3}$.

Table 2: Water resistance of composites with density of $0.9-1 \mathrm{~g} / \mathrm{cm}^{3}$.

\begin{tabular}{|l|ll|l|l|}
\hline $\begin{array}{l}\text { Binder content } \\
{[\%]}\end{array}$ & $\begin{array}{l}\text { Content } \\
\text { additive [\%] }\end{array}$ & $\begin{array}{l}\text { Water uptake } \\
{[\%]}\end{array}$ & $\begin{array}{l}\text { Moisture } \\
\text { expansion [\%] }\end{array}$ \\
\hline 15 & 0 & 58 & 30 \\
\hline 15 & 1.5 & 22 & 14 \\
\hline 25 & 0 & 31 & 13 \\
\hline 25 & 1.5 & 16 & 6 \\
\hline
\end{tabular}

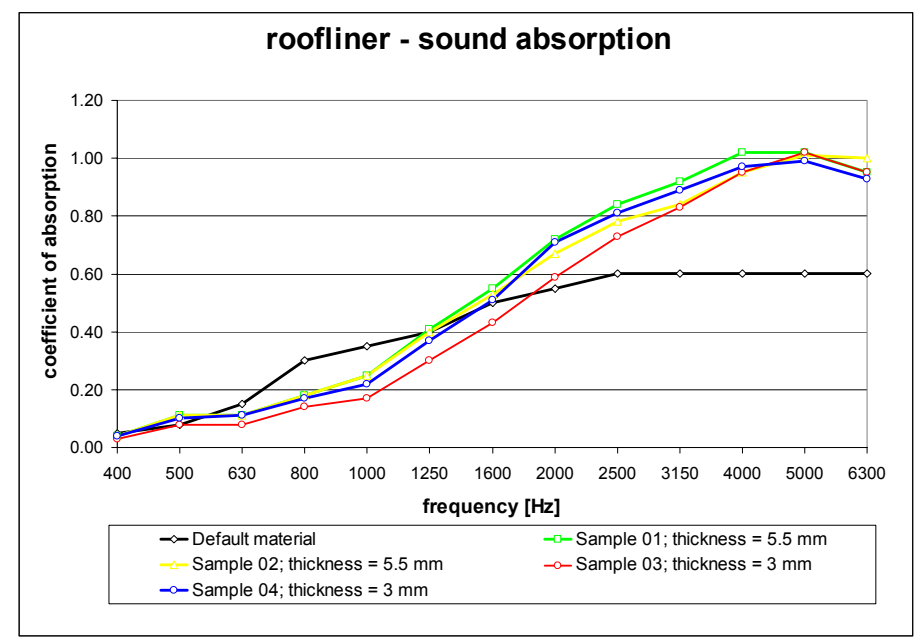

Figure 8: Sound absorption of roofliners.

\subsection{Acoustic properties}

Nonwovens with an area weight of $750 \mathrm{~g} / \mathrm{m}^{2}$ and a binder content of $25 \%$ are produced by the foulard dyeing technology. The impregnated mats are moulded to roofliners and proved in a reverberant chamber. The measured absorbance of the samples is compared with a default material. 
The acoustic properties are an interesting aspect for applications like roofliners. A roofliner is usually a sandwich construction composed of a foamed core layer between two reinforcing laminates as top layers (=default material). The foamed core acts as sound-absorber. The composite material composed of natural fibres and acrylic resin has a good sound-absorbance. If the frequency is higher than $1250 \mathrm{~Hz}$ the composite is better than the compared default material.

\section{Summary}

A new composite material based on natural fibres as reinforcement and an acrylic thermoset as binder was developed with the following results:

- The foulard dyeing technology is the best choice to impregnate both thin and thick nonwovens composed of natural fibres continuously without risk to exceed the engine power limit or to damage the fibres.

- Advantages for the fabricator:

- The fabricator doesn't need to impregnate the mats immediately before moulding

- The impregnated mats have a good storage stability compared to other thermosets

- The acrylic resin has a very good environmental impact (no phenol and formaldehyde)

- A reduction of weight of moulded parts can be realised $(-20 \%)$ without losing of mechanical properties.

- A low binder content of $15-20 \%$ is sufficient for binding.

- To improve the water uptake and moisture expansion of the moulded composites a hydrophobizing agent is necessary (1.5\% is sufficient).

- In comparison to composites with thermoplastic binder the dimensional stability under heat is excellent.

\section{References}

[1] Albrecht W., Fuchs H., Kittelmann W. NonWoven Fabrics Raw Materials, Manufacture, Applications, Characteristics, Testing Processes. Verlag Wiley-Vch. 2003.

[2] Clark T. K., R.L. Cunningham, and Wolff I. A. A search for new fiber crops. 1971. TAPPI 54; (1) p. 63-65.

[3] Dambroth. Seehuber. Flachs: Züchtung, Anbau und Verarbeitung. 1988.

[4] Reck B., Türk J. Thermally curable aqueous acrylic resins - a new class of duroplastic binders for wood and natural fibers. 2nd International Wood and Natural Fiber Composites Symposium. Kassel, Germany. June 28-29, 1999.

[5] Oberbach K., Baur E., Brinkmann S., Schmachtenberg E. Saechtling Kunststoff Taschenbuch. 29. Ausgabe. Verlag Carl Hanser. 2004.

[6] Bledzki A. K., Gassan J. "Natural Fiber Reinforced Plastics" in Handbook of Engineering Plastics. N.P. Cheremisinoff (editor). M. Deccer Inc. New York. 1997. p. 787-809. 